\title{
FreGsd: A Framework for Global Software Requirement Engineering
}

\author{
Alsahli Abdulaziz Abdullah ${ }^{1 *}$, Hameed Ullah Khan ${ }^{2}$ \\ ${ }^{1}$ King Saud University, Riyadh, Saudi Arabia. \\ 2 Information Systems Department, King Saud University, Riyadh, Pakistani. \\ ** Corresponding author. Tel: 00966543337201; email: alsahli9@ymail.com \\ Manuscript submitted April 25, 2015; accepted June 18, 2015. \\ doi: 10.17706/jsw.10.10.1189-1198
}

\begin{abstract}
Software development nowadays is more and more using global ways of development instead of normal development environment where development occurs in one location. This paper is aimed to propose a requirement engineering framework to support Global Software Development environment with regards to all requirement engineering activities from elicitation to finally managing requirement change. Global software environment is more and more gaining better reputation in software development with better quality is resulting from developing in this environment yet with lower cost. However, failure rate developing in this environment is high due to inappropriate requirement development and management. This paper will add to the software engineering development environments discipline and many developers in GSD will benefit from it.
\end{abstract}

Key words: FreGsd, global software development environment, GSD, requirement engineering.

\section{Introduction}

In recent years a new way emerged to develop software as a result of globalization and international connection between different firms and developers located in different countries of the world, this type of development now known to researchers and developers as global software environment. Software in this new environment cannot be developed using same requirement engineering techniques that is used in normal environments. A failure rate in software development using this environment is high due to inappropriate requirement elicitation and management. We aim to examine the most recent RE techniques used in GSD and then we will develop a framework for requirements engineering in this environment. Following sections define requirement engineering and global software environment and then compare and contrast some frameworks that have been suggested by other researcher in the field and finally a proposed framework will be introduced.

\section{Requirement Engineering}

It is very important to understand requirement engineer as a concept in general and it is clear from literature that the term have been in use for long time and one of the pioneers who describe requirement engineering as an emerging term very early is Jawad and Chandra as they suggest that "requirements engineering is often used as a contractual exercise in which the customer and the developer organizations work to reach agreement on a precise, unambiguous statement of what the developer would build"[1]. Requirement engineering activities include elicitations of requirement, modeling and analyzing 
requirement, communicating and agreeing requirement and finally evolving requirements[2]. from our experience as system analysts and academics, we can name goal-driven and even decompression as the most important techniques used nowadays. And for modeling we can suggest UML diagrams as best up to date modeling techniques. Communicating requirement can be seen as both communications between different stakeholders for reaching final agreement on suggested requirement and also can be seen as communication between different development team members. And finally evolving requirement can be seen as the ability to manage the change in requirement effectively.

\section{Global Software Development (GSD)}

In the recent year and due to the globalization which hugely effected by ease of communication via internet, a new way of development of software has emerged in which best use of resources available elsewhere in world with geographical separated locations for development is now known as GSD. James explain "Globally-distributed projects are rapidly becoming the norm for large software systems, even as it becomes clear that global distribution of a project seriously impairs critical coordination" [3]. We can easily see many benefits for development using this new way, like benefiting from human expertise may not found locally and also the salaries of software development teams and establishment expenses can be very lower elsewhere e.g. the cost of hiring a programmer in India cannot be compare to cost of hiring same qualifications and experience level in U.S.A or Europe. It is also clear to many who work in this type of environment that it suffers many drawback and challenges like differences between team's members who assigned to work on a certain project, those differences include cultural, language and time differences. Arif came to a conclusion that communication is the major challenge in GSD after researching different risks and caused of each risks he explained "GSD is not a simple task and the organizations face different challenges. But Communication is a major issue and it becomes more complicated during the process of Requirements" [4]. Language barrier can be dealt with by choosing a team leader from every site of developments, choosing of such personal should take into account his language, communication and technical capabilities as he is the one who will be the point of communication to other development members overseas. Other challenges is the initial team building and travel cost between different development's locations if needed and finally it is important to notice that the lack of lunch and tea break conversations that exist in the in-house development which usually help developers to communicate in project related issue which is proven to be effected is also an extra drawback. Monasor found that many developers in this new environment has no prior knowledge and experience in developing in GSD environment so they suggested a simulator that works as a training tool for companies in which the developers will work in real project via virtual agents of different locations and cultures [5] (see Fig. 1).

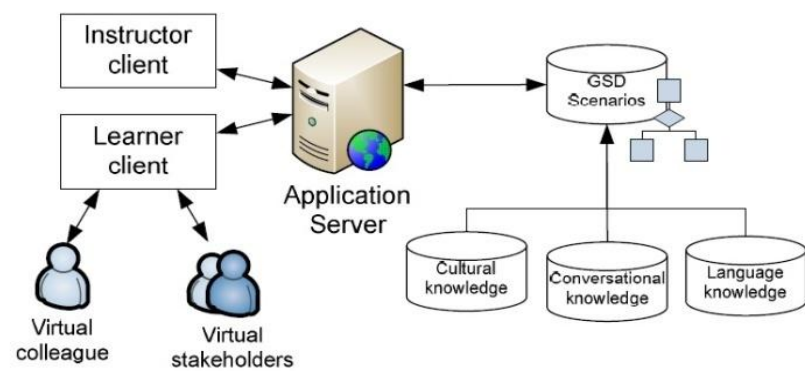

Fig. 1. Simulator environment proposed by Monasor [5].

According to Global service location index by A.T Kearney [6], India and then China are the top attractive destination for off shoring and interestingly Egypt is in Fourth place which give us a good indication of low labor cost and good quality personnel available in Egypt (see Fig. 2) . 


\begin{tabular}{|l|l|l|l|l|l|}
\hline Rank & Country & $\begin{array}{l}\text { Financial } \\
\text { attractiveness }\end{array}$ & $\begin{array}{l}\text { People skills } \\
\text { and availability }\end{array}$ & $\begin{array}{l}\text { Business } \\
\text { environment }\end{array}$ & Total score \\
\hline 1 & India & 3.11 & 2.76 & 1.14 & 7.01 \\
2 & China & 2.62 & 2.55 & 1.31 & 6.49 \\
3 & Malaysia & 2.78 & 1.38 & 1.83 & 5.99 \\
4 & Egypt & 3.10 & 1.36 & 1.35 & 5.81 \\
5 & Indonesia & 3.24 & 1.53 & 1.01 & 5.78 \\
6 & Mexico & 2.68 & 1.60 & 1.44 & 5.72 \\
7 & Thailand & 3.05 & 1.38 & 1.29 & 5.72 \\
8 & Vietnam & 3.27 & 1.19 & 1.24 & 5.69 \\
9 & Philippines & 3.18 & 1.31 & 1.16 & 5.52 \\
10 & Chile & 2.44 & 1.27 & 1.82 & 5.51 \\
11 & Estonia & 2.31 & 0.95 & 2.24 & 5.48 \\
12 & Brazil & 2.02 & 2.07 & 1.38 &
\end{tabular}

Fig. 2. Top 12 countries by A.T Kearney global service location 2011[6].

\section{Requirement Engineering for Software Development in GSD}

Daniela Damian have study requirement engineering in GSD in depth and from her own past experience in this filed she think that "Due to its communication and collaboration-intensive nature, as well as inherent interaction with most other development processes, the practice of requirements engineering is becoming a key challenge in global software engineering (GSE)" [7]. She think that requirement engineering practice in GSD is totally different that the practice in normal environments and one of the most important factor causing this difference is that the stakeholders in GSD is usually geographically distributed in many locations and hence the initial determination of requirement and any later change in any requirement needs to be coordinated between many stallholders before validating the requirement. Damian identify 3 main processes in requirement engineering that the stakeholders must go through to achieve a common understanding of requirement engineering in GSD as follow : Knowledge Acquisition for the requirement, then a process that is done iteratively to reshape this requirements and finally an effective coordination between different stakeholders for any future change in requirement [7]. Siffat examined deeply the factors that is either help to success or to fail in any project in GSD in which he abbreviate it as Offshore Software Development Outsourcing OSDO by doing a SLR and then he concluded that "Most of the existing studies focus on the topics of 'outsourcing relationship' and 'outsourcing trust', which are important areas to address. However, research suggests that half of the companies that have tried outsourcing have failed to realize projected results. There are many reasons for such outsourcing failures. One of the major issues in the outsourcing business is to find an outsourcing vendor that is capable of undertaking the outsourcing activities required."[8] so it is very clear to researchers in the field that failure to understand the requirement in GSD initially via requirement elicitation and validation and then to manage any change in the requirement later on is a major reason for failure in software development in global enviroment.Helena study different major challenges in GSD and classify them in three distant dimensions : Temporal which is related to time difference between different development location, geographical which is related to physical travel between different development location if media was not enough and physical attendance of stakeholders in certain development location is needed and finally social and cultural distance which we describe early as difference in languages and holiday times and other cultural issues between different development location [9]. Tervonen made a research of multiple case studies of 5 Finnish companies who use GSD before and they all located in Oulu and he used interviews, questionnaires and observations as tools in his study and he concluded that "The changing requirements were noticed as a problem in every case. In the case P3, the requirements were of substandard quality. They were collected from previous materials, stored in multiple locations, and resulted in conflicting requirements. The case P6, on the other hand, accepted the changing requirements as a part of the software development industry despite the fact that they were problematic"[10].Khan think that the challenges in dealing with requirement in GSD is due to the distribution of team members and them being away from other stakeholders "Requirement engineers face challenges in dealing with distributed team members and clients for communicating the 
requirements of the developing software. These challenges are faced due to ignoring the contextual characteristics" [11], She named several factors that influence each activity of requirement engineering activities on GSD and conclude that understanding and stating requirement was the most influence factor in almost every activity [11].

\section{Related Work}

Depth read in the literature revealed that only few researchers has participated in this new field and not much sophisticated academic work have been done yet if any, and this is due to the fact that this type of geographically distributed environment have been in use only in recent years. Niazi have studies 5 organizations whom already adapting this environment for software development and compared their requirement engineering practice against best 66 requirement engineering practice suggested by Sommerville and his result revealed that those organizations have not perceived those best practice well and as a consequence they did not apply them in their work in GSD environment and base on his empirical study result he suggested a framework for helping to a better understand of requirement process in GSD [12]. Kumari suggest that requirement elicitation is the most important activity in requirement engineering and therefore it needs the most attention, therefore he suggested a framework for requirement elicitation base on both literature review and practitioners views, his work is still under progress. He conducted interview with practitioner as well as document analysis and then compare the result from practitioners with result from document analysis for determining elicitation dimensions and them modeling of elicitation dimensions and finally conduct a survey to validate the model [13]. Arif explain that he revised the literature and found no one else have proposed a framework for RCM in GSD before him [14] and hence he came up with a framework for managing requirement change in distributed environment (see Table 1).

Table 1. Related Frameworks Compared to FreGsd

\begin{tabular}{|c|c|c|c|c|}
\hline $\begin{array}{l}\text { Proposed } \\
\text { framework }\end{array}$ & Scope & Used Method & Pros & Cons \\
\hline $\begin{array}{l}\text { GlobReq by } \\
\text { Niazi }\end{array}$ & $\begin{array}{l}\text { All } \\
\text { activates }\end{array}$ & $\begin{array}{l}\text { Compare RE best practice with } 5 \\
\text { organizations by conducting } \\
\text { empirical study }\end{array}$ & Studied best RE Practice & $\begin{array}{l}\text { Framework still not } \\
\text { available to evaluate }\end{array}$ \\
\hline Kumari & $\begin{array}{l}\text { Elicitation } \\
\text { only }\end{array}$ & $\begin{array}{l}\text { Based in Literature review and } \\
\text { practitioners views }\end{array}$ & $\begin{array}{l}\text { Compare single elicitation } \\
\text { factor with overall RE success }\end{array}$ & Limited scope \\
\hline Arif & $\begin{array}{l}\text { Change } \\
\text { Only }\end{array}$ & $\begin{array}{l}\text { Based in Literature review and case } \\
\text { study of several organizations }\end{array}$ & $\begin{array}{l}\text { First one to proposed } \\
\text { framework for RCM in GSD }\end{array}$ & Limited Scope \\
\hline $\begin{array}{l}\text { FreGsd by } \\
\text { Alsahli }\end{array}$ & $\begin{array}{l}\text { All } \\
\text { Activities }\end{array}$ & Base on SLR and Expert views & $\begin{array}{l}\text { Framework } \\
\text { Implementation, } \\
\text { evaluation enhancement }\end{array}$ & None \\
\hline
\end{tabular}

\section{Problem Statement}

This research carried out after the identification of the lasting problem of requirement engineering practice in GSD which cause the high failure rate of many project developed in distributed environment and the literature revealed that the most common cause of such failure is not proper requirement development and management due to Cultural, geographical, temporal and linguistic distances. Many factors contributed to this difficulties and eventfully failure due to RE in distributed environment, one is that this type of environment is new and developing is such environment is untried long enough as well as other problems contributed to the failure like communication and collaboration complexity in such environment cause the requirement elicitation, specification, verification and management a big headache and a growing reason for failure.

\section{Research Questions}


The research questions can be summarized as following:

RQ1: What are the problems associated with requirement elicitation, specification, verification and management in GSD environment?

RQ2: What is the best practice and lesson learned for requirement elicitation in GSD environment? RQ3: What is the best practice and lesson learned for requirement specification in GSD environment? $\mathrm{RQ} 4$ : What is the best practice and lesson learned for requirement verification in GDS environment? $\mathrm{RQ5}$ : What is the best practice and lesson learned for requirement management in GSD environment?

RQ6: How do we benefit from both best practice and lesson learned in developing a new project using distributed environment?

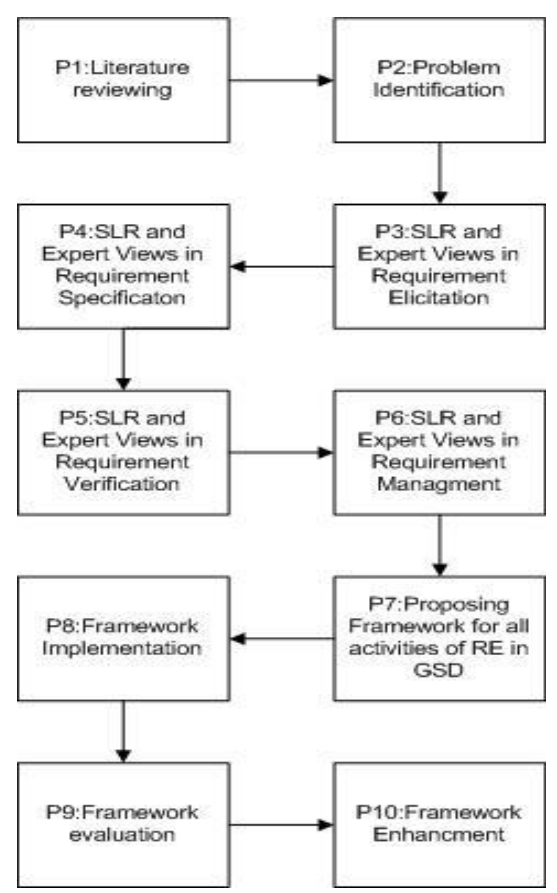

Fig. 3. Phases of FreGsd framework.

\section{Proposed Framework}

The purpose of FreGsd (Framework for requirement engineering in global distributed environment) is to participate for a better understating for requirement engineering activates and practice for project developed in follow the sun or distributed environment. It main objective is to overcome and avoid the current practice that causes the higher failure rate because of such practice in such environment due to requirement immature handling with regard to all activates of requirement engineering .First we will conduct a systematic literature review to identify both lesson learned and best practice for the requirement engineering in GSD in all requirement activities and to answer research questions. The process of SLR will start first by identifying the main books, papers or any other material relevant to research questions then extraction of items in those materials needed to answer the research questions and finally analyzing those items and merging them in such a way that can help to answer six research questions. A review protocol to conduct SLR is going to be defined before starting systematic literature reviewing. Then we will interview some domain expert for a list of both lesson learned in case of failure or best practice in case of success with regard to both requirement development and requirement management in their organization which already developed projects using distributed environment. The criteria for choosing the expert and final expert list as follows: 
1) The expert should have experience dealing with requirement handling in GSD. Expert experience can be in one requirement activity or all. However researcher considers the final expert list should have all experts in all requirements activates.

2) Some experts should come from a failure background for deep understanding of lesson learned yet expert list should also have a success background for best practice of requirement development and management.

3) The expert list should have a minimum of one expert in coordination between different development sites.

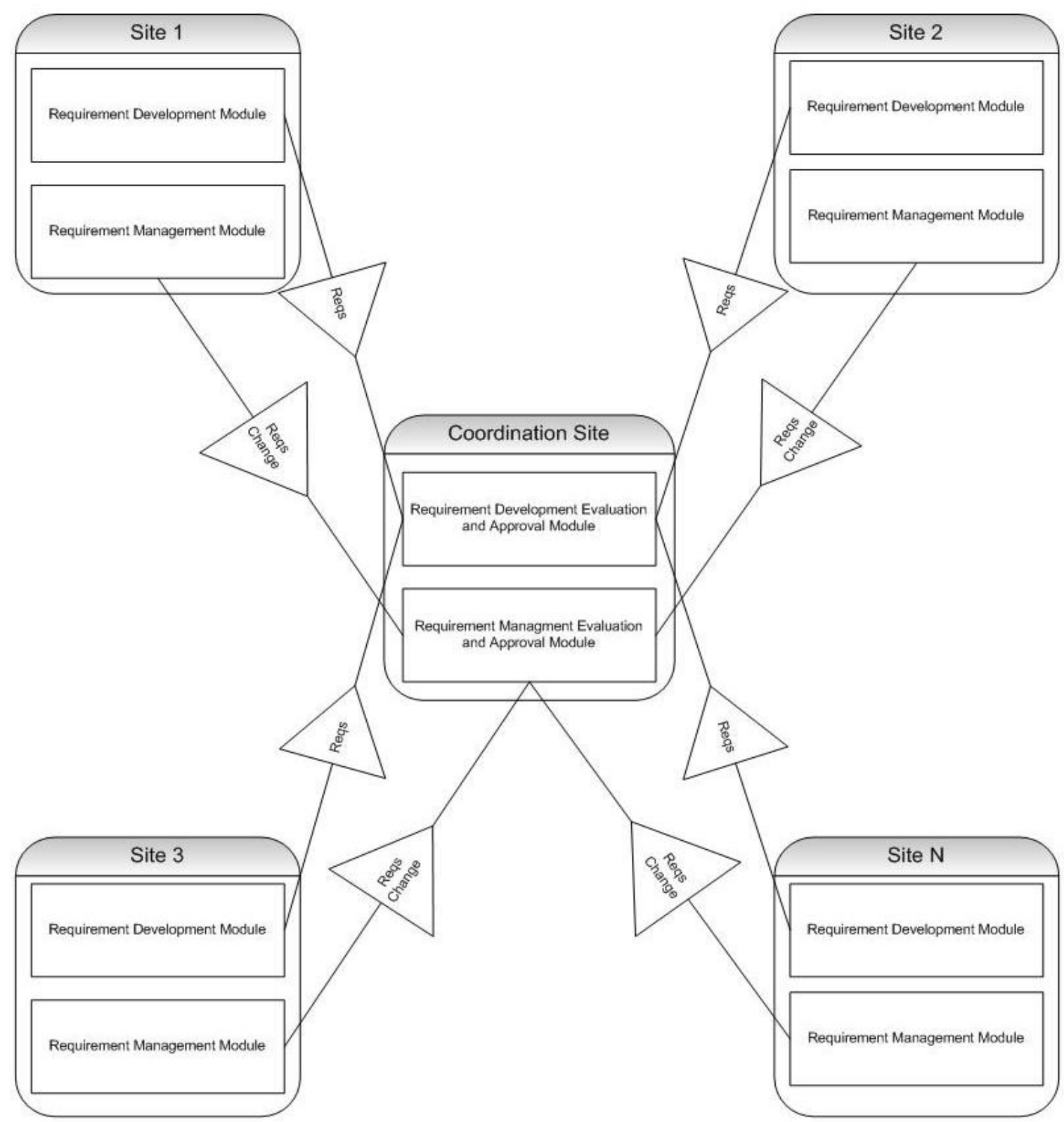

Fig. 4. Conceptual Architecture for FreGsd framework.

The FreGsd consist of four main modules: Requirement development module, requirement management module, requirement development evaluation and approval module and requirement management evaluation and approval module. Both requirement development and requirement management module is responsible for coordination and of requirement internally within each development site. Requirement 
management module is mainly deals with requirement change. Requirement development and management evaluation and approval module receive new requirement and request for requirement change from different geographically distributed sites and then coordinate those requirements and then evaluate them to decide either to approve them or reject them as well as the ability the trace requirement.

When a new requirement is coming from any stakeholder or quality assurance personnel it is submitted to local change manager who will examine its impact and consistency over other requirement and then specify formally and model it , then it forward to Change Control Board to decide whether to accept it or reject. Fig. 3 shows different phases of this module. And it is clear from Fig. 3 that it is the responsibility of local site manager to prepare the specification for the new requirement that normally includes model and technical specification of the new requirement and in case local quality assurance in the initiator the new requirement ,they also can be involved in the specification of this requirement. States in each module are graphically explained in the following figures:

Fig. 5 shows different phases when a change in requirement in trigged, reasons for change can be change in stakeholders need or change to add more quality to the software, when a new change request is placed Site- $\mathrm{N}$ manger evaluates it impact and consistency over other requirements and if it show no conflict then site- $\mathrm{N}$ manger forward to Change Control Board for final approval.

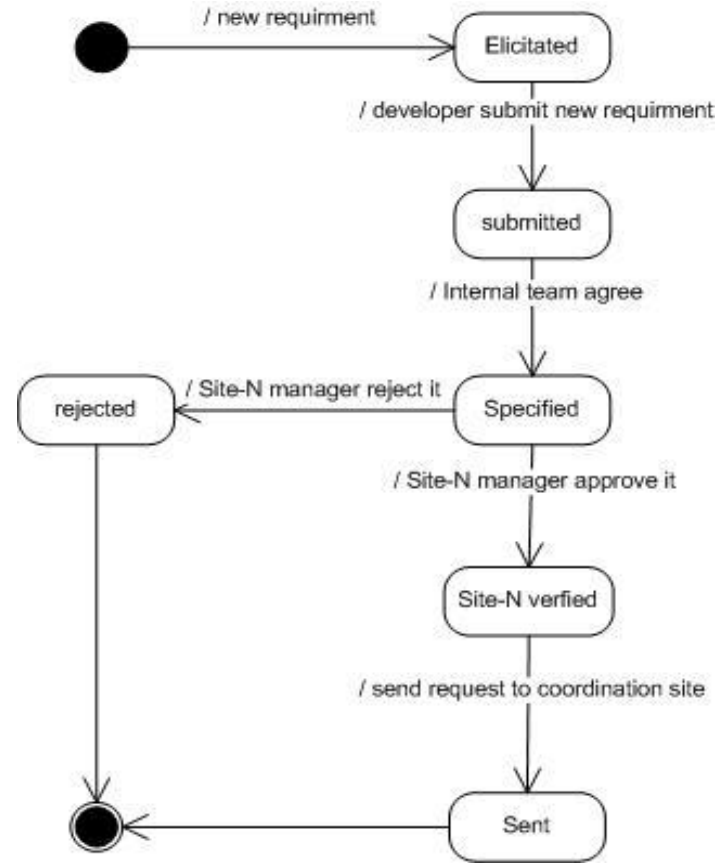

Fig. 5. State machine diagram for requirement development module.

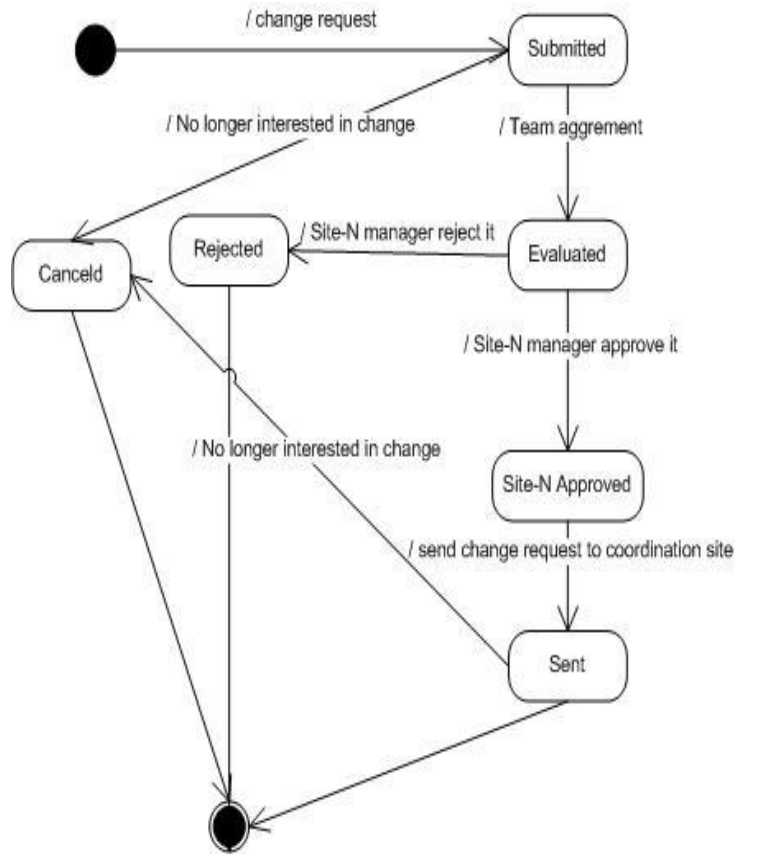

Fig. 6. State machine diagram for requirement management module

Fig. 7 and Fig. 8 both done on a global level and they comes after the submission of new requirements or request for change coming from site- $\mathrm{N}$ manager. Fig. 7 show different states that of requirements after Change Control Board receive a request from distributed sites and before either approval or rejection of the request. A new requirement is coming from site- $\mathrm{N}$ manger is first received and then forward to coordination team to check that this requirement has not already been requested before this time. if coordination team found prior similar requirement and no major change or cost is expected then integration with previous requirement is recommended. If the coordination team found this requirement new and no previous similar requirement is available, then they check its consistency and impact with other requirement, also check if it is within the scope of the project, if both is valid then this request is 
initially accepted and then it forward to Change Control Board or mangers to final evaluation and a decision about approval or rejection is on their hand based on previous evaluation.

Fig. 8 shows in details different steps since a local manger of site- $\mathrm{N}$ submit a request for change to Change Control Board and Coordination team. Coordination team checks both if this change has no impact and consistent with other requirement and if it pass this initial test, it also check wheatear it is within project scope or beyond it. If both tests is passed then it is initially accepted by coordination team and then it is send to Change Control Board for final evaluation and a decision where to accept or reject this request for change.

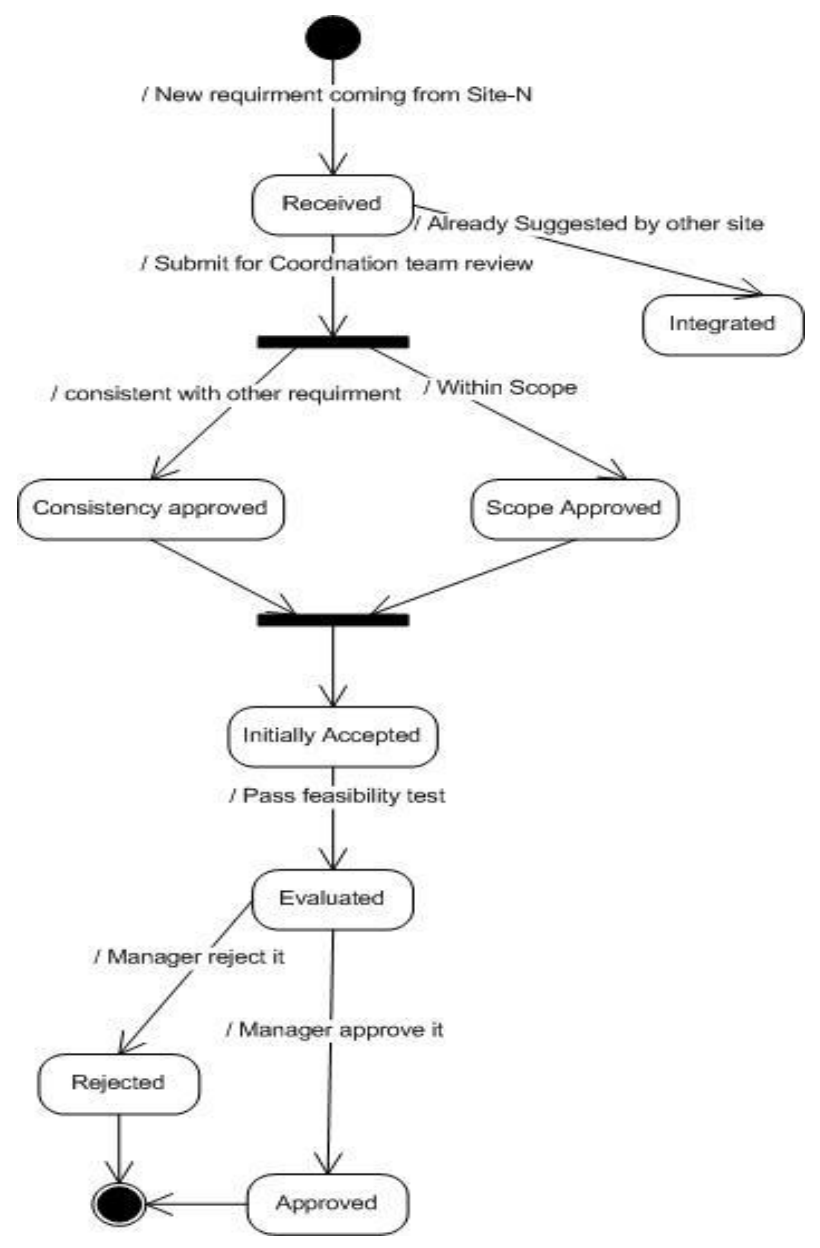

Fig. 7. State machine diagram for requirement development evaluation and approval module.

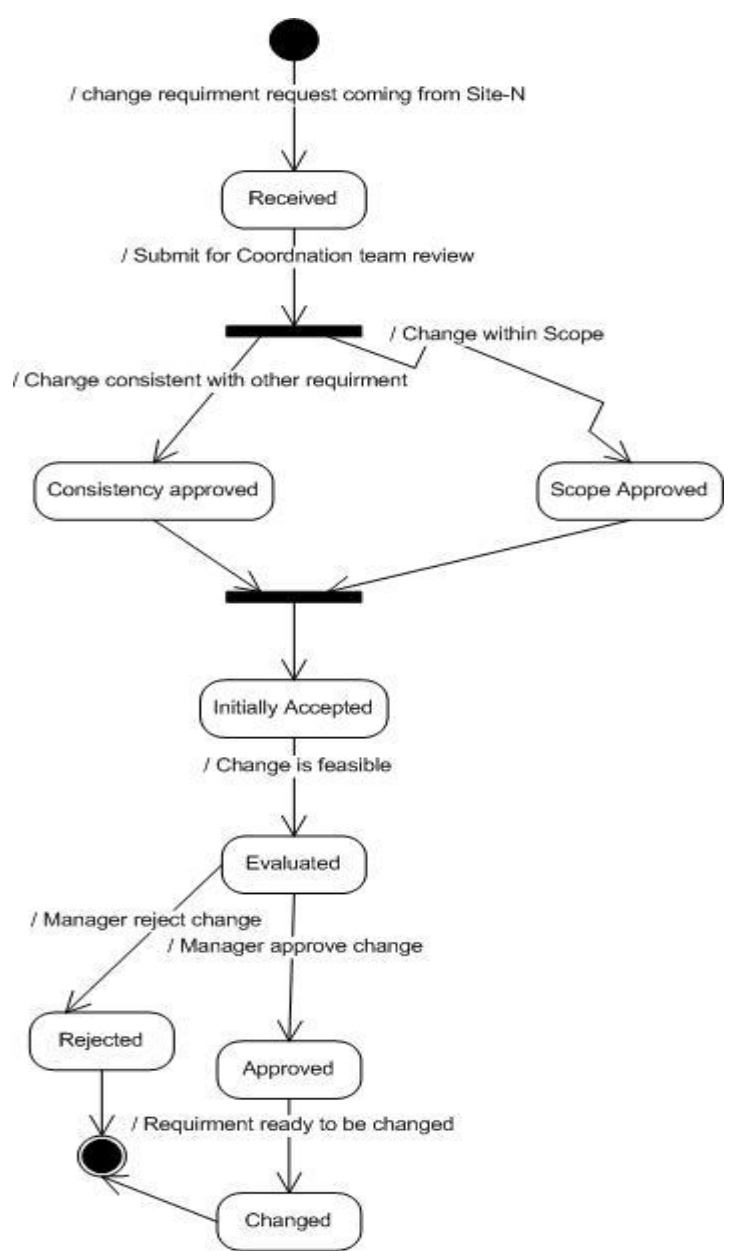

Fig. 8. State machine diagram for requirement management evaluation and approval module.

\section{Conclusion}

Development in distributed environment suffers from more complexity and complications than development of software in normal environment. The complexity increase while dealing with new requirement and request for change in requirement coming from different development geographically distributed sites. The purpose of this research is to address the communication and collaboration between different development sites with regards to developing and managing requirements. FreGsd is a framework aiming to help organizations developing in distributed environment to avoid common mistakes that lead to frequent failure and to apply best practices to maximize the productivity and to develop and manage requirements in globally distributed environments. Future work includes evaluation of FreGsd by inviting organization to use it and provide feedback and based on that an enhancement and continuous 
improvement will be introduced to the framework.

\section{Acknowledgment}

We are grateful to the Research Centre (RC), College of Computer and Information Sciences (CCIS), for extending us all categories of support and continuous assistance during this research work. We are also thankful to all those who contributed in any form to make this research successful. Thanks are also due to the Dean CCIS and the Chairman Information Systems Department, for their continuous support and time to time encouragement.

\section{References}

[1] Siddiqi, J. (1996). Requirement engineering: The emerging wisdom. IEEE Software, 13, 15.

[2] Nuseibeh, B., \& Easterbrook, S. (2000). Requirements engineering: A roadmap. Proceedings of the Conference on the Future of Software Engineering (pp. 35-46).

[3] Herbsleb, J. D. (2007). Global software engineering: The future of socio-technical coordination. presented at the 2007 Future of Software Engineering, 2007.

[4] Khan, A. A., Basri, S., \& Dominic, P. D. D. (2014). Communication risks in GSD during RCM: Results from SLR. presented at the International Conference on Computer and Information Sciences (ICCOINS).

[5] Monasor, M. J., Vizcaíno, A., \& Piattini, M. (2010). A training tool for global software development. presented at the 9th International Conference on Information Technology Based Higher Education and Training (ITHET) Cappadocia 2010.

[6] Kearney, A. T. Global service location. Retrieved October, 2014. from http://www.atkearney.com/gbpc/global-services-location-index/past-report/-/asset_publisher/i9mY sV84tcQx/content/offshoring-opportunities-amid-economic-turbulence-the-a-t-kearney-global-servic es-location-index-2011/10192?_101_INSTANCE_i9mYsV84tcQx_redirect=\%2Fgbpc\%2Fglobal-service s-location-index\%2Fpast-report

[7] Damian, D. (2007). Stakeholders in global requirements engineering: Lessons learned from practice. IEEE software, 24(2), 21-27.

[8] Khan, S. U., Niazi, M., \& Ahmad, R. (2011). Factors influencing clients in the selection of offshore software outsourcing vendors: An exploratory study using a systematic literature review. J. Syst. Softw., 84(4), 686-699.

[9] Holmstrom, H., Conchúir, E. Ó., Ågerfalk, P. J., \& Fitzgerald, B. (2006). Global software development challenges: A case study on temporal,geographical and socio-cultural distance. presented at the IEEE International Conference on Global Software Engineering (ICGSE'06).

[10] Tervonen, I., Haapalahti, A., Harjumaa, L., \& Simila, J. (2013) Outsourcing software testing: A case study in the oulu area. presented at the 13th International Conference on Quality Software, Najing.

[11] Khan, H. H., \& Bin, M. M. N. R. (2014). Situational requirement engineering framework for global software development. presented at the International Conference on Computer, Communications, and Control Technology (I4CT), Langkawi, Malaysia.

[12] Niazi, M., El-Attar, M., Usma, M., \& Ikram, N. (2012). GlobReq: A framework for improving requirements engineering in global software development projects: Preliminary results. Presented at the 16th International Conference on Evaluation \& Assessment in Software Engineering (EASE 2012), Ciudad Real.

[13] Neetu, K. S., \& Pillai, A. S. (2013). A survey on global requirements elicitation issues and proposed research framework. presented at the 2013 4th IEEE International Conference on Software Engineering and Service Science (ICSESS), Beijing. 
[14] Khan, A. A., Basri, S., \& Dominic, P. D. D. (2012). A propose framework for requirement change management in global software development. presented at the 2012 International Conference on Computer \& Information Science (ICCIS), Kuala Lumpeu 2012.

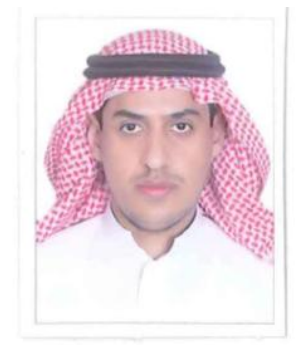

Mr Abdulaziz Alsahli is currently a PhD candidate at King Saud University in Saudi Arabia. His current work in PhD thesis is related to requirements engineering and global software development. In 2009, Abdulaziz was rewarded his master degree in information systems from City University in London. 